\title{
Early readmission in a high complexity public hospital in cardiology
}

\author{
Readmissão precoce em hospital público de alta complexidade em cardiologia
}

Herminia Ricci ${ }^{1}$, Mara Nogueira de Araújo $^{1}$, Sérgio Henrique Simonetti ${ }^{1}$

Objective: to evaluate the early readmission of patients in a high complexity public hospital in cardiology. Methods: this is a descriptive, documental and retrospective study, carried out in a public hospital. Results: in 2012,729 of the 9,218 hospitalized patients were readmitted, $47.9 \%$ of them were readmitted within 30 days after discharge, $61 \%$ were men, with a mean age of 57 years old, with the main medical diagnosis of heart disease (heart failure, treatment of acute coronary syndrome, among others) on admission (44.7\%) and readmission (45.8\%). Most were readmitted for the same medical reason that led to their first hospitalization. Conclusion: considering the profile of the population admitted and readmitted to the institution, it is believed that the rate of readmission is mainly due to the profile of the patients, considering the high prevalence of non-communicable chronic diseases, and coronary artery disease considered unapproachable for percutaneous or surgical when hospitalized.

Descriptors: Patient Readmission; Nursing; Hospitalization; Length of Stay.

Objetivo: avaliar a readmissão precoce de pacientes em hospital público de alta complexidade em cardiologia. Métodos: estudo descritivo, documental e retrospectivo, realizado em instituição pública hospitalar. Resultados: dos 9.218 pacientes internados, em 2012, 729 foram readmitidos, destes, 47,9\% reinternaram dentro de 30 dias após a alta hospitalar, sendo 61\% homens, idade média de 57 anos, tendo o principal diagnóstico médico de doenças cardíacas (insuficiência cardíaca, tratamento de síndrome coronariana aguda, entre outros) na admissão $(44,7 \%)$ e na readmissão $(45,8 \%)$. A maioria foi readmitida pela mesma razão médica que motivou a primeira hospitalização. Conclusão: em consideração ao perfil da população admitida e readmitida na instituição, acredita-se que a taxa de readmissões se deve, principalmente, ao perfil dos pacientes, ponderando a alta prevalência de doenças crônicas não transmissíveis, e doença arterial coronariana considerada inabordável para tratamento percutâneo ou cirúrgico na admissão.

Descritores: Readmissão do Paciente; Enfermagem; Hospitalização; Tempo de Internação.

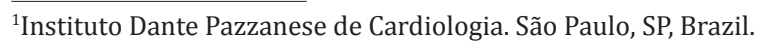




\section{Introduction}

Early hospital readmission is considered an indicator of the quality of health care. In addition to discomfort to the patient, insecurity and possible complication of treatment lead to expenses to the health system, necessary to evaluate the profile of patients readmitted early.

Studies have used different intervals since discharge to define readmission, such as rehospitalization in 72 hours, more than 72 hours, one week, one month and up to one year after discharge ${ }^{(1-6)}$. This study considered early analysis within the first 30 days of patient readmission.

Hospital readmissions can be classified as planned and eventual, those necessary to the continuity of the treatment or diagnostic evaluation. The eventual ones are grouped in potentially avoidable and non-avoidable. Some readmissions are considered potentially avoidable because they associate the indicators with poor care during hospitalization, the low resolution of the initial problem, inadequate postdischarge care, and unstable therapy at discharge. Also, it is hypothesized that the lower the interval, the greater the possibility of readmission being due to a potentially preventable complication ${ }^{(7-8,5)}$.

Readmission brings questions to the patient and family: "What went wrong?" To the provider: "What did I do wrong?" And, to the health system: "How are we going to prevent this from happening again?" Moreover, "Will that cost us?"

It assumes that, as a result of the increase in costs for the Unified Health System and unnecessary conditions of discontent for the patient and family, it is relevant that health professionals obtain knowledge about the factors involved in the hospital readmission to improvement in care and re-planning of postdischarge care $^{(9)}$.

Analyzing hospitalized and readmitted patients in this institution, being those with a cardiological care profile, it is necessary to understand the pathological profile. Since the 1960s, we have seen an increase in morbidity and mortality due to nontransmissible chronic diseases, particularly diseases of the circulatory system, which are the main cause of death in all Brazilian regions, characterized by: an insidious installation process, a long asymptomatic course, a generally slow, prolonged and permanent clinical course, with evolution to varying degrees of incapacity or death ${ }^{(10)}$.

In 2007, cardiovascular diseases represented the third cause of hospitalizations for the Unified Health System, with Heart Failure being the most frequent cause of hospitalization, which is a worldwide public health problem ${ }^{(11-12)}$.

Readmission may occur within 30 days after discharge, target of this study, and may be due to worsening of the patient's previous condition, poor prognosis, as well as other associated morbidities.

There are studies that have evaluated predictors of readmission in an intensive care unit $^{(1)}$. Therefore, they identified that almost one in 10 patients undergoing percutaneous coronary intervention were readmitted within 30 days $^{(13)}$, and this period was associated with a higher mortality risk at one year. However, they showed that health cost is associated with worse prognosis in the long term ${ }^{(14-15)}$, which adds the need for more studies that address the theme and highlight the importance of research in knowledge gaps.

With regard to nursing care provided in the immediate post-discharge period and at the first moment of readmission, as well as in relation to the follow-up of this group after the nursing intervention, addressing the topics with teaching strategy, certain variables, and their possibilities of correlate were not found in specific scientific studies, located a single study that emphasizes the need for nurses to propose systematized actions with patients with heart failure, leading to an understanding of their disease and decreasing decompensation ${ }^{(16)}$.

Knowledge about patient readmission may lead to future planning and implementation of strategies that may decrease potentially preventable 
readmissions, becoming an indicator of the quality of care after hospital discharge. This study aimed to evaluate the early readmission of patients in a high complexity public hospital in cardiology.

\section{Methods}

This is a descriptive, documentary and retrospective design study. Data collection was performed at a public hospital institution of the State Health Department of São Paulo, Brazil, a reference in cardiology care in the State.

The data collection took place in two stages: firstly, the survey and analysis of the occurrence of readmission of patients in 2012, in the database of the Medical and Statistical Archive Service, regarding: age, origin, hospitalization unit, agreement, medical diagnosis in hospitalizations, time interval between hospitalizations, time of hospitalization; The data were then collected in the medical records of these patients regarding: gender, marital status, education, occupation, labor situation, comorbidities (diabetes mellitus, systemic arterial hypertension, dyslipidemia, smoking, obesity, sedentary lifestyle and stress). (Nursing diagnoses and potential problems in hospitalization, on the day before discharge and the first day of re-hospitalization) and cause of death, when present. This second documentary stage was carried out by a previously elaborated instrument.

In 2012, there were 9,218 patients admitted to the institution, of which 728 patients were readmitted within the same year. This sample was selected according to the inclusion criteria: patients with no established age, who were discharged in 2012 and were readmitted in the Institution in the same year. Afterward, the sample was filtered to select patients who returned within 30 days, and we obtained a sample of 349 patients, who were present in this study.

The 41 medical diagnoses in the first and second hospitalizations were categorized into: Arrhythmias (atrial flutter ablation and arrhythmia treatment), (treatment of complications of surgical or clinical procedure, implantation of valve prostheses, heart transplantation, correction of asymmetric septal hypertrophy, correction of single ventricle, correction of coarctation of the aorta, myocardial revascularization and valve replacement with myocardial revascularization), Cardiac diseases (coronary angioplasty, intraluminal vessel angioplasty, long-term care, cardiac catheterization, cardiogenic shock, percutaneous mitral valvuloplasty, treatment of chronic ischemic heart disease, treatment of hypertensive crisis, treatment of rheumatic disease with cardiac involvement, treatment of insufficiency Cardiomyopathies and treatment of acute coronary syndrome), Congenital diseases (treatment of congenital malformations of the circulatory system), Endovascular diseases (endovascular correction of abdominal aortic aneurysm/dissection, vessel intraluminal angioplasty, limb arteriography, limb arteriography, embolization of arteriovenous vascular malformation, and endovascular correction of aneurysm), Infectious diseases (treatment of other bacterial diseases), Neurological diseases (resection of intracranial tumor and treatment of uncontrolled epileptic seizures), Renal diseases (acute renal failure, kidney transplantation, treatment of chronic renal failure and long-term catheter implantation), Respiratory diseases (treatment of diseases of the respiratory system, treatment of respiratory diseases and treatment of other respiratory diseases), Vascular diseases (arteriography for cerebral ischemia investigation, stroke treatment, surgical treatment of varicose, treatment of arterialinsufficiency with critical ischemia, treatment of arterial insufficiency with critical ischemia, debridement of ulcer/devitalized tissue, treatment of deep venous thrombosis), Exams (computed tomography and biopsy and anatomy-cytopathological examination), Pacemaker (pacemaker evaluation, temporary pacemaker implantation, transvenous and transvenous double chamber pacemaker implantation) and others (Gastrointestinal Diseases, Genitorian Diseases, Hematologic Diseases, Infectious Diseases, Metabolic 
Diseases and Dental Treatment).

The data were transcribed to a worksheet prepared in Microsoft Excel 2010 and submitted to statistical analysis with the program Statistical Package for the Social Sciences, version 19.0, using parametric and non-parametric tests (significance level of 5.0\%). The analysis of the association of categorized medical diagnoses and hospitalization and re-hospitalization units, categorized medical diagnoses and nursing diagnoses, categorized medical diagnoses, and age (Student's t-test, Spearman, and Pearson) was performed; Comparison of clinical and nursing status (Fisher's exact test and chi-square test).

The study complied with the formal requirements contained in the national and international regulatory standards for research involving human beings.

\section{Results}

There were 349 (47.9\%) readmitted within 30 days of the 728 patients admitted and readmitted in 2012, that is from hospital discharge to the second hospital stay, of which $61.0 \%$ were men, with a mean age of 57 years old, mostly married (56.7\%), with incomplete elementary school (32.4\%), retired (41.0\%).

During the first hospitalization, the number of days in the institution ranged from zero to 118 , averaging 10 days, with the main medical diagnosis at admission being Cardiac Diseases (44.7\%), followed by Vascular Diseases (15.8\%). The most frequent comorbidities were Arterial Hypertension (70.9\%), followed by Sedentarism (50.0\%), Dyslipidemia (49.1\%), Diabetes Mellitus (29.1\%), Stress (17.7\%) and Obesity (11.9\%).

The emergency room was the main entrance of the patients at the first admission with diagnosis of Respiratory Diseases (100.0\%), Infectious Diseases (100.0\%), Arrhythmia (61.9\%), Cardiac (59.0\%), Pacemaker (50.0\%), Renal (47.1\%) and Others (100.0\%). The mean number of days between the first and second admissions was 12 days.

The main entry unit at the second admission was also the Emergency Room, covering $100.0 \%$ of patients with Infectious Diseases, 88.9\% Respiratory, 62.5\% Vascular, 56.0\% Surgical, 50.0\% Pacemaker, 43.2\% Endovascular, 42.9\% Arrhythmias, 42.9\% Renal, $41.3 \%$ with Cardiac Diseases and $41.8 \%$ Others.

The main medical diagnosis on readmission was Cardiac Disease (45.8\%), followed by Endovascular Diseases (10.6\%) and Congenital Diseases (10.6\%), as shown in Table 1.

Table 1 - Distribution of the main medical diagnoses on the first and second admission

\begin{tabular}{lcc}
\hline \multirow{2}{*}{ Medical Diagnosis } & Main admission & Second admission \\
\cline { 2 - 3 } Heart diseases & n (\%) & $\mathbf{n}(\%)$ \\
Vascular diseases & $55(15.8)$ & $160(45.8)$ \\
Congenital diseases & $40(11.5)$ & $8(2.3)$ \\
Coronary disease & $30(8.6)$ & $37(10.6)$ \\
Arrhythmias & $21(6.0)$ & $14(4.0)$ \\
Renal diseases & $17(4.9)$ & $14(4.0)$ \\
Endovascular diseases & $9(2.6)$ & $14(4.0)$ \\
Pacemaker & $8(2.3)$ & $37(10.6)$ \\
Respiratory diseases & $4(1.1)$ & $8(2.3)$ \\
Other & $4(1.1)$ & $9(2.6)$ \\
Infectious diseases & $2(0.6)$ & $13(3.7)$ \\
Surgical & $1(0.3)$ & $6(1.7)$ \\
Neurological diseases & $1(0.3)$ & $25(7.2)$ \\
Exams and Diagnostics & $1(0.3)$ & $1(0.3)$ \\
\hline
\end{tabular}

From the patients who presented Infectious Disease in the first hospitalization, $50.0 \%$ returned to the diagnosis of Heart Disease and $50.0 \%$ with diagnosis of Renal Disease. Who in the first hospitalization presented the diagnosis of Neurological Disease, in the second hospitalization entered as Surgical. Who gave entrance as Exams in the second hospitalization returned with the diagnosis of Endovascular Disease.

Regarding the age, we can observe that, regardless of the medical diagnosis, the mean remained in 60 years old, except Congenital Diseases, which had an average of 14 years (0.6-67). 
Regarding the Nursing Diagnostics at the first admission, the deficient knowledge about the present procedure was identified in $44.4 \%$ of patients with Endovascular Diseases and $23.6 \%$ in Vascular Diseases $(\mathrm{p}<0.01)$.

About the nursing diagnoses in the second admission, the Self-care for bathing/hygiene deficit was present in $100.0 \%$ of patients with Infectious Diseases, 88.9\% with Respiratory Diseases and 72.0\% of Surgical patients $(\mathrm{p}<0.01)$. The acute pain was in $21.4 \%$ of patients with coronary disease and $20.0 \%$ of surgical patients $(\mathrm{p}<0.05)$. Arterial insaturation present in $18.9 \%$ of cases of Congenital Diseases $(\mathrm{p}<0.01)$. Impaired tissue integrity was in $76.0 \%$ of surgical patients $(\mathrm{p}<0.01)$. Impaired physical mobility was in $100.0 \%$ of patients with Infectious Diseases, 87.5\% with Pacemaker and $57.5 \%$ with Cardiac Diseases $(\mathrm{p}<0.01)$.

We obtained the diagnosis, Intermittent family processes in $10.8 \%$ of the patients with Congenital Diseases $(\mathrm{p}<0.05)$. The risk of constipation was in $100.0 \%$ of patients with Respiratory Disease $(\mathrm{p}<0.05)$. The risk of unstable glycemia was in $87.5 \%$ of patients with Pacemaker and $60.0 \%$ of Surgical patients $(p<0.01)$. The risk of infection present in $94.6 \%$ of patients with Congenital Diseases $(\mathrm{p}<0.05)$. The risk of falling in $100.0 \%$ of patients with Pacemaker and $100.0 \%$ of those with Infectious Diseases $(p<0.05)$. Break in the family bond present in $78.4 \%$ of patients with Congenital Diseases and 64.3\% with Coronary Disease $(\mathrm{p}<0.01)$.

There were 38 of the 349 patients studied who died at some time of readmission, having as main cause septic and cardiogenic shock.

\section{Discussion}

The population was mostly male, with a mean of 57 years old, admitted and readmitted with a prevalence of the diagnosis of heart disease. These data agree with the literature, which adult men readmitted early and with the same diagnosis ${ }^{(3,5,7,17)}$.
Because it was a cardiological institution, the most prevalent diagnosis was Cardiac Disease, with the treatment of heart failure as the first cause, followed by treatment of the acute coronary syndrome. Vascular and Endovascular Diseases also had a considerable portion of admissions and readmissions.

Diagnoses not considered cardiac have also been present, such as Respiratory, Infectious, Renal and other diseases. This is because the emergency room is characterized as an "open door," where cardiological screening is not done, all of which are attended, although it is a specialized hospital.

Most were readmitted for the same medical reason that motivated the previous hospitalization, as observed heart disease, congenital diseases, endovascular diseases, pacemaker and others. Only three diagnoses were not kept on readmission. This was because the intervention was readmitted, as in the case of those who entered as Exams and Diagnoses and in readmission as Endovascular Disease, or who admitted with Neurological Disease and readmitted as Surgical. These readmissions can be considered as planned $^{(3)}$.

A comparison of the overall prevalence of hospital readmission within 30 days with previous studies shows that the readmission rate of this study was high - 47.9\% of patients readmitted in 2012 returned less than 30 days, as opposed to the $10.2 \%$ found $^{(5)}$ and similar to the $51.1 \%$ identified $^{(7)}$ in another study. Some readmissions can be considered potentially avoidable: procedures not performed at the first hospitalization, lack of diagnosis defined at the first hospitalization, and lack assistance in the primary care ${ }^{(3)}$. According to the study, readmissions ${ }^{(4)}$ between zero and 10 days can be considered avoidable.

Analyzing other studies, readmissions in the adult population are more susceptible in patients with chronic noncommunicable diseases and their progressive staging, mostly cardiovascular diseases and pulmonary pathologies, and these patients with sensitive conditions need primary health $\operatorname{care}^{(3,5)}$.

Regarding the nursing care, no studies were 
found to address care and readmission. In this study, the most prevalent nursing diagnosis and potential problem identified at admission were the Self-care deficit for bathing and hygiene, present in patients with Arrhythmia, Cardiac Diseases, Respiratory Diseases, Vascular Diseases and Pacemaker.

The medical diagnosis with the greatest number of nursing diagnoses and potential problems was Cardiac Diseases, with the following diagnoses: Self-care deficit for bath and or hygiene, Pain related to chest pain, Impaired physical mobility, Ineffective protection, Risk for debt Cardiac risk decreased, Risk of constipation, Risk of unstable glycemia, Risk of Infection, Risk of Falls, Sleep deprivation and Excessive volume of fluid. When assessing the number of nursing diagnoses and/or potential problems, it is assumed that cardiac patients enter the service with high dependence on nursing care.

By the analysis of the readmission, it can be observed that the nursing diagnoses are more prevalent in the following medical diagnoses: Self-care deficit for bath/hygiene in the diagnoses Infectious, Respiratory and Surgical diseases; and, Impaired physical mobility in the diagnoses of Infectious Diseases, Pacemaker, and Heart Diseases. The medical diagnosis with more nursing diagnoses was the Surgical, that is, the patients who were readmitted and submitted to an invasive procedure. It was observed that the medical diagnosis that most demanded nursing care at admission was Cardiac Disease and in the Surgical readmission, with a greater number of nursing diagnoses.

This study had as a limitation because the difficulty of establishing the predictors, signs, and symptoms in the readmission, since medical and nursing diagnoses, were collected as data of the collection. In this way, there is no evaluation of the moment of readmission, also because it is a retrospective study, suggesting a case-control and prospective study.

\section{Conclusion}

The readmission of the patients in this study occurred mainly in the emergency department, suggesting a shortage of health care, especially at the outpatient level for chronic noncommunicable diseases. On the other hand, emergency services often have inadequacies in meeting the needs of patients with such a profile, due to the high demand, whether due to early discharge or failure to manage information, causing the individual to return with the same diagnosis of the previous admission or the evolution of the disease, which could potentially be avoided.

Despite the difficulty in establishing a consensual interval to consider an early hospital readmission, readmissions can be useful in evaluating the quality of the service and patient understanding and care, since they involve markers of multi-professional care and the service where it is performed, and to the condition of the patient.

\section{Collaborations}

Ricci H contributed to the concept and design, analysis and interpretation of the data, writing the article and finally approving the version to be published. Araújo MN and Simonetti SH contributed to the design of the study, analysis and interpretation of data, critical review of the intellectual content and final approval of the version to be published.

\section{References}

1. Piper GL, Kaplan LJ, Maung AA, Lui FY, Barre $\mathrm{K}$, Davis K. Using the Rothman index to predict early unplanned surgical intensive care unit readmissions. J Trauma Acute Care Surg. 2014; 77(1):78-82.

2. Kramer AA, Higgins TL, Zimmerman JE. Intensive care unit readmissions in U.S Hospitals: Patient characteristics, risk factors, and outcomes. Crit Care Med. 2012; 40(1):3-10. 
3. Batista CSDG, Silvino ZR. Profile of readmission patients in a state hospital of Rio de Janeiro. Rev Enferm UFPE on-line [Internet]. 2015 [cited 2016 Jul 14]; 9(12):1296-300. Available from: http:// www.revista.ufpe.br/revistaenfermagem/index. php/revista/article/viewArticle/7084

4. Yam $\mathrm{CH}$, Wong EL, Chan FW, Leung MC, Wong FY, Cheung AW, et al. Avoidable readmission in Hong Kong - system, clinician, patient or social factor? BMC Health Serv Res [Internet]. 2010 [cited 2016 Jul 14]; 10(311):2-11. Available from: http://bmchealthservres.biomedcentral.com/ articles/10.1186/1472-6963-10-311

5. Bianco A, MolèA, Nobile CG, Di Giuseppe G, Pileggi C, Angelillo IF. Hospital readmission prevalence and analysis of those potentially avoidable in Southern Italy. PLoS One [Internet]. 2012 [cited 2016 Jul 14]; 7(11):48263. Available from: https://www. ncbi.nlm.nih.gov/pubmed/23133624

6. Calvillo-King L, Arnold D, Eubank K, Lo M, Yunyongying P, Stieglitz H, et al. Impact of Social Factors on Risk of Readmission or Mortality in Pneumonia and Heart Failure: Systematic Review. J Gen Intern Med. 2013; 28(2):269-82.

7. Borges MF, Turrini RNT. Readmissão em serviço de emergência: perfil de morbidade dos pacientes. Rev Rene. 2011; 12(3):453-61.

8. Laskey WK, Ricciardi MJ. 30-day Readmission rate following percutaneous coronary intervention much more than a binary variable. J Am Coll Cardiol Intv. 2013; 6(3):245-6.

9. Borges FK, Soliman F, Pires DO, Seligman R. Reinternação hospitalar precoce: avaliação de um indicador de qualidade assistencial. Rev HCPA. 2008; 28(3):147-52.
10. Abreu DMX, Drumond EF, França EB, Ishitami LH, Malta DC, Machado CJ. Análise comparativa de classificações de causas evitáveis de morte em capitais Brasileiras: o caso das doenças cerebrovasculares. Rev Bras Estud Popul. 2010; 27(2):447-55.

11. Bocchi EA, Marcondes-Braga FG, Bacal F, Ferraz AS, Albuquerque D, Rodrigues D, et al. Atualização da Diretriz Brasileira de Insuficiência Cardíaca Crônica - 2012. Arq Bras Cardiol. 2012; 98(1 supl 1):1-33.

12. Chitsaz S, Wenk JF, Ge L, Wisneski A, Mookhoek A. Material properties of cor cap passive cardiac support device. Ann Thorac Surg. 2013; 95(1):14854.

13. Khawaja FJ, Shah ND, Lennon RJ, Slusser JP, Alkatib AA, Rihal CS, et al. Factors associated with 30-day readmission rates after percutaneous coronary intervention. Arch Intern Med. 2012; 172(2):1127.

14. Yost GW, Puher SL, Graham J, Scott TD, Skelding $\mathrm{KA}$, Berger PB, et al. Readmission in the 30 days after percutaneous coronary intervention. J Am Coll Cardiol Intv. 2013; 6(3):237-44.

15. Kansagara D, Englander H, Salanitro A, Kagen D, Theobald C, Freeman M, et al . Risk prediction models for hospital readmission: a systematic review. JAMA. 2011; 306(15):1688-98.

16. Machado FB, Vicentin ES. Fatores precipitantes de readmissões de pacientes portadores de insuficiência cardíaca descompensada. Rev Soc Cardiol. 2012; 22(3 suppl):8-12.

17. Bisharat N, Handler C, Schwartz N. Readmissions to medical wards: analysis of demographic and socio-medical factors. Eur J Intern Med. 2012; 23(5):457-60. 